\title{
A pioneering healthcare model applying large-scale production concepts: Principles and performance after more than 11,000 transplants at Hospital do Rim
}

\author{
José Medina Pestana ${ }^{1 *}$
}

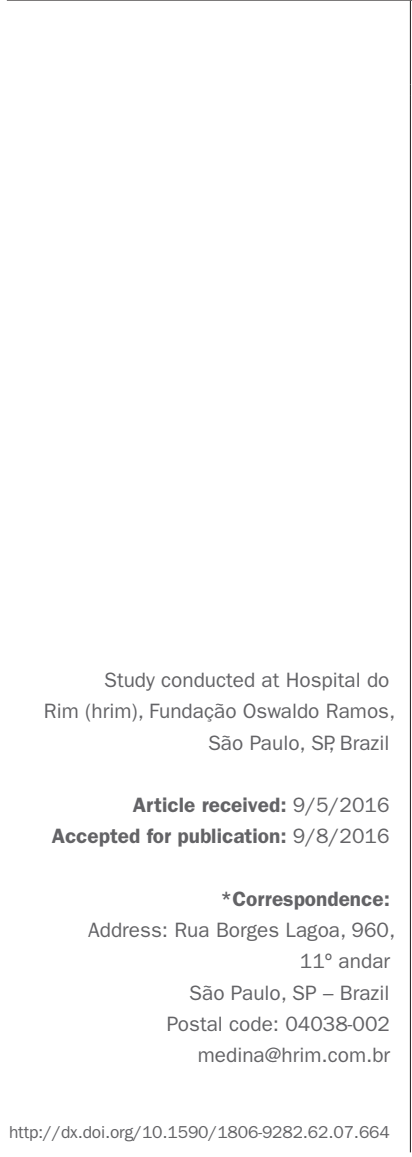

\section{SUMMARY}

The kidney transplant program at Hospital do Rim (hrim) is a unique healthcare model that applies the same principles of repetition of processes used in industrial production. This model, devised by Frederick Taylor, is founded on principles of scientific management that involve planning, rational execution of work, and distribution of responsibilities. The expected result is increased efficiency, improvement of results and optimization of resources. This model, almost completely subsidized by the Unified Health System (SUS, in the Portuguese acronym), has been used at the hrim in more than 11,000 transplants over the last 18 years. The hrim model consists of eight interconnected modules: organ procurement organization, preparation for the transplant, admission for transplant, surgical procedure, post-operative period, outpatient clinic, support units, and coordination and quality control. The flow of medical activities enables organized and systematic care of all patients. The improvement of the activities in each module is constant, with full monitoring of various administrative, health care, and performance indicators. The continuous improvement in clinical results confirms the efficiency of the program. Between 1998 and 2015, an increase was noted in graft survival (77.4 vs. 90.4\%, $\mathrm{p}<0.001)$ and patient survival $(90.5 v$ s. $95.1 \%, \mathrm{p}=0.001)$. The high productivity, efficiency, and progressive improvement of the results obtained with this model suggest that it could be applied to other therapeutic areas that require large-scale care, preserving the humanistic characteristic of providing health care activity.

Keywords: kidney transplantation, tissue and organ procurement, renal insufficiency, Unified Health System.

\section{INTRODUCTION}

Brazil, one of the few countries with universal health coverage established in its Federal Constitution and provided by the Unified Health System (SUS), ${ }^{1}$ has developed health care models that exceed the expectations of a developing country. Health programs that include nationwide vaccination, treatment of patients infected with the HIV virus, and organ transplants are examples of international significance. ${ }^{2}$

Brazil has the second largest national transplant program, second only to the United States. Every year around 8,000 solid organ transplants are performed, 5,556 of which are kidney transplants, ${ }^{3}$ with more than $90 \%$ under the SUS system, making it the world's largest public program in this therapeutic area. The regulation of the program and coordination of the procurement and distribution of organs are carried out by the $\mathrm{Na}$ tional Transplant System (SNT), a public service created in 1997, and put into operation by the Notification, Procurement and Organ Distribution Centers (CNCDO) and Organ Procurement Organizations (OPO) established in the 27 State Departments of Health.

Hospital do Rim (hrim), one of the main players in this system, began a unique medical care model in 1998, aimed at conducting at least one kidney transplant per day. ${ }^{4}$ As such, it has been perfecting this model using concepts from the systematic repetition of processes, as applied in industrial production and published in 1911 by Frederick Taylor in his book The principles of scientific management, which is still poorly applied in healthcare. These principles 
involve scientific planning, rational and broken-down execution of the work, and the distribution of roles and responsibilities based on each personal development. The goal of this process is greater production, quality and systematic attainment of established goals. In this model the patient passes through specialized health care modules until the post-transplant period, when they are preferably treated by a single physician. As a consequence of this model, the annual number of transplants has gradually grown over this 18-year period, with over 850 kidney transplants conducted annually since 2009 (Figure 1). ${ }^{5}$ These results have made the hrim the largest international kidney transplant center, treating patients from all regions of Brazil and, similar to what is done in the national transplant program, more than $90 \%$ of these activities are performed through the SUS. ${ }^{6}$ In this article, we describe this medical model in detail and the results obtained over the last 18 years, aware that it could be applied in other clinical situations of health assistance, as well as in other regions.

\section{Program structure}

The hrim, administered by the Oswaldo Ramos Foundation, has 151 hospital beds, with 16 in the intensive care unit, six in the immediate post-operative unit and nine in a day hospital unit. The surgical center offers four rooms and six beds for post-anesthetic recovery. All of the physicians employed by the hospital completed a medical residency in their respective specialty, and most of them are involved in graduate programs. The application of the large-scale production concepts is monitored weekly through analysis of the main clinical and administrative indicators, enabling early correction of deviations or distortions. ${ }^{7}$

\section{Module A: Organ Procurement Organization (OPO)}

In the regions of Greater São Paulo and Baixada Santista, with 21,000,000 inhabitants, the entire organ donation process is coordinated by four OPOs. The OPO at Escola Paulista de Medicina (OPO-EPM), administered by the Oswaldo Ramos Foundation, operates in a region of 6,000,000 inhabitants, with 75 hospitals in the Greater São Paulo and Baixada Santista. The team is made up of two coordinators, that is, a nephrologist and a nurse, alongside ten nurses divided into daily shifts and a team of surgeons dedicated to kidney extraction. This team carries out extensive supplementary activity to spread and consolidate the culture of organ donation in society, including the promotion of educational and training courses for physicians and hospital coordinators, in addition to routine visits to hospitals in the region. ${ }^{8}$

\section{Module B: Preparation for the transplant}

Registration, clinical assessments, and preparation of candidates for kidney transplants with living or deceased donors are carried out in this module, including simultaneous pancreas and kidney transplant candidates. After a first contact, which may be by telephone or e-mail, the first evaluation is scheduled within a maximum of 2 weeks. The service is carried out daily and conducted by a multidisciplinary team that includes nephrologists, surgeons, cardiologists, and a social worker. The risks and benefits of the transplant are discussed with potential donors and recipients.

Registration and preparation for the transplant with a living kidney donor includes the identification of the donor based on clinical criteria and blood and genetic compatibility, according to SNT regulations. All of the tests required for assessment of donor and recipient as well as evaluations with specialists are scheduled and carried out at the hrim, thereby avoiding difficulties and inefficiencies in the scheduling of laboratory tests and medical evaluations at several clinics. The steps involved in preparing the patient for the transplant are controlled using algorithms, preventing unnecessary delays, until the date of the transplant is scheduled.

The registration of transplant candidates with a deceased donor involves a clinical and laboratory assessment, including serologic tests for communicable diseases. Registration on the waiting list is based on blood type (ABO). During this evaluation, genetic typing of the candidate's HLA system is scheduled at the immunogenetics laboratory, which advises them to store a serum sample every 3 months for the completion of crossmatching (antibodies against the donor's HLA system in the serum of the recipient). Clinical reassessment and reorientation of the candidates are conducted annually, with complementary tests repeated according to clinical recommendations.

\section{Module C: Admission for transplant}

For transplants with kidney from a living donor, both the recipient and the donor are admitted on the eve of surgery, with clinical reassessment and a detailed review of all laboratory and genetic compatibility tests. Routine preoperative tests for surgery of medium complexity are carried out. The risks and benefits of organ transplantation are discussed with the donor and the recipient again, followed by the signing of a consent form for donation and transplantation. The surgery is elective, and normally carried out early in the morning on the following day. 
For kidney transplants from deceased donor, the identification of potential recipient is conducted by the State Department of Health and is based primarily on the ABO blood type identity and higher compatibility with the donor's HLA genetic system from among all active candidates on the waiting list. Candidates identified and registered at our transplant center are then contacted by phone using a structured interview to assess their current medical conditions. Based on this interview, the potential candidate is invited to immediately undergo preoperative tests and clinical examinations. Once the recipient is defined, the risks and benefits of organ transplantation are once again discussed before signing a consent form to perform the transplant. The average time between the identification of the candidate and admission to the operating room is around 20 hours.

\section{Module D: Surgical procedure}

The surgical team is composed of eight urologists and two urology residents per year, divided into set teams from Monday to Friday and on-call shifts on weekends. The duration of the kidney transplant surgery varies from 90 to 120 minutes, while nephrectomy of a living donor varies between 60 to 90 minutes. General anesthesia is applied to both the donor and the recipient. Donor nephrectomy is performed through an anterior lumbotomy incision, and on the recipient is performed using a modified Gibson incision with vascular anastomosis to the iliac vessels and the ureter on the bladder according to the Gregoir or Politano-Leadbetter technique. The implantation of ureteral catheters and drainage of the renal area are not performed routinely. ${ }^{9}$ For deceased donors, both kidneys are removed en bloc, most often associated with the removal of the abdominal or thoracic organs, with participation of multiple teams.

\section{Module E: Post-operative period}

After surgery, the donors and recipients are maintained in the immediate post-operative unit, where they remain for the first 18 to 24 hours. During this period, they are under the care of a specialized team that monitors clinical and surgical complications in addition to initiating treatment with immunosuppressants according to predetermined protocols.

Patients are conducted, from admission to discharge, at one of the four units with 30 beds, each of which managed by two of the hospital's physicians, divided into 6-hour shifts, in addition to night and on-call physicians. All clinical and surgical activity is coordinated by one nephrologist and one urologist, with the routine clinical support of three infectious disease doctors, two cardiologists, and two pathologists. Daily visits and hospital discharge are multidisciplinary with subsequent automatic scheduling of the first evaluation at the outpatient unit.

\section{Module F: Outpatient clinic}

The outpatient department includes ten consulting rooms, three nursing stations, and an emergency room, while management is coordinated by a senior nephrologist. Coordination of clinical care is performed by two experienced nephrologists, one in the morning and another in the afternoon. The health care flow is linear, starting with a nursing evaluation and followed by medical, pharmaceutical, psychological, and social work services, and ending with the scheduling of the following evaluation and obtainment of the necessary documentation for the dispense of medication at public pharmacies.

The evaluations follow a predetermined schedule, the frequency of which is higher in the first months and then quarterly a year after the first year of transplant. Laboratory tests can be performed in the morning, with results available on the same day. Daily attendance is performed by a specialized medical team, with an average of 16 patients per 5-hour shift per physician. The coordinators guide the majority of evaluations, especially when they involve changes in conduct or immunosuppression regimen. Patients who have health insurance can follow a similar flow, or can be forward for monitoring with their referring physician. Few patients are monitored solely by their referring nephrologists, even when they live in other states. Elective hospital readmissions are coordinated directly by the outpatient department. Emergency care is provided at the hospital emergency unit.

\section{Module G: Support units}

The model has complete care provided by independent support units: (1) dialysis treatment unit; (2) day hospital unit; (3) immunogenetics laboratory; (4) clinical pathology laboratory; (5) hospital infection control committee (CCIH); (6) diagnostic imaging unit; (7) urological investigation and intervention unit; (8) interventional cardiology unit; (9) renal pathology unit.

The immunogenetics laboratory (IGEN) performs all of the genetic tests on patients registered for transplantation at the hrim. The clinical laboratory, diagnostic imaging, and renal pathology units provide diagnostic support 24 hours a day. In addition to the determination of the blood concentration of various immunosuppressive drugs, the clinical laboratory con- 
ducts all of the routine tests, and releases the final results on the same day as collection. Biological samples are taken by two groups of technicians, with capacity to attend up to ten patients simultaneously. The day hospital has nine beds for less complex procedures, such as kidney biopsies, and 16 stations for outpatient intravenous drug administration. Units for dialysis treatment, urological investigation and intervention, and cardiology provide diagnostic and therapeutic support both before and after the transplant. Lastly, in addition to promoting and monitoring hospital infection control measures, with special attention to multiresistant bacteria, the hospital infection control committee also works on advising patients, family members and employees about the behavior and prevention of epidemics such as dengue fever and influenza, which are a greater risk for transplant patients.

\section{Module H: Coordination and quality control}

Consists of a systematic meeting designed to be the first morning activity on the first day of the week (Monday, at 7:30 am to 8:30 am) involving the leaders of the modules described above and members of the senior management, with the aim of monitoring the performance of each module, benchmarking, and improvement of processes. This activity is aimed at the most thorough, close and personal cooperation between participants, with equitable division of the work and responsibilities among the leaders for maximum performance, applying the concepts of scientific management through the presentation of indicators. Leading and management activities are directed towards coordinated work with their groups of collaborators, disseminating the indicators of results, and seeking maximum individual and collective prosperity, considering that even tasks with systematic repetition must be reviewed for permanent improvement.

\section{Program outcomes}

Increase in the number of deceased donors

The number of brain death notifications by hospitals in the region of the OPO-EPM increased from 196 in 1999 to 684 in 2015. The number of effective donors (potential donors whose organs were actually donated and transplanted) increased from 43 to 202 in the same period. The efficiency of the process is characterized by the reduction in the percentage of family refusal of donation, falling from 78 to $43 \%$, and the increase in the donation effectiveness in the same period, from 22 to $29 \%$ (Table 1).

\begin{tabular}{|c|c|c|}
\hline Productivity indicators & 1999 & 2015 \\
\hline Effective deceased donors & 43 & 202 \\
\hline $\begin{array}{l}\text { Patients on the waiting list for transplant with } \\
\text { kidneys from deceased donors }\end{array}$ & 3,050 & 5,303 \\
\hline Total transplants & 394 & 886 \\
\hline Adult with kidney from a living donor & 271 & 205 \\
\hline Adult with kidney from a deceased donor & 96 & 617 \\
\hline Pediatric with kidney from a living donor & 22 & 4 \\
\hline Pediatric with kidney from a deceased donor & 5 & 44 \\
\hline Simultaneous pancreas-kidney transplants & 0 & 16 \\
\hline Cumulative number of transplants & 503 & 12,724 \\
\hline $\begin{array}{l}\text { Cumulative number of transplant recipients } \\
\text { under monitoring }\end{array}$ & 439 & 7,751 \\
\hline Number of evaluations at the outpatient department & 7,295 & 59,781 \\
\hline
\end{tabular}

Increase in the number of transplants

Between August 18, 1998 and December 31, 2015, 11,707 transplants were conducted at hrim, with 10,580 kidney transplants in adults, 856 pediatric kidney transplants and 271 simultaneous pancreas and kidney transplants. Over this 18-year period, the annual number of transplants has increased more than twice, from 394 in 1999 to 886 in 2015 (Figure 1). Linear growth was observed between 1999 and 2008, a period in which kidney transplants from living donors predominated. Between 2009 and 2015 the number of transplants has remained relatively stable at 856 to 919 , but with a predominance of kidney transplants from deceased donors (76\%). The same phenomenon was observed with pediatric transplants, with an increase of 27 to 74 transplants between 1999 and 2009, and subsequent stabilization and predominance of kidney transplants from deceased donors (Figure 1). Finally, the number of simultaneous kidney and pancreas transplants remains relatively stable at around 30 per year, with a decrease last year following an international trend, possibly justified by advances in pharmacological and glycemic control, as well as improved methods for the administration of insulin.

Currently, the hrim has 5,303 candidates registered on the kidney transplant waiting list and 338 for the combined pancreas and kidney transplant, which corresponds to 50\% of the total number of candidates from the city of São Paulo registered on the single list $(11,149)$ of the Health Secretariat (Table 1). The number of evaluations held for registration or annual reassessment of transplant candidates using a kidney from a deceased donor was 5,926 in 2015. In 2015, the number of registrations for performing kidney 


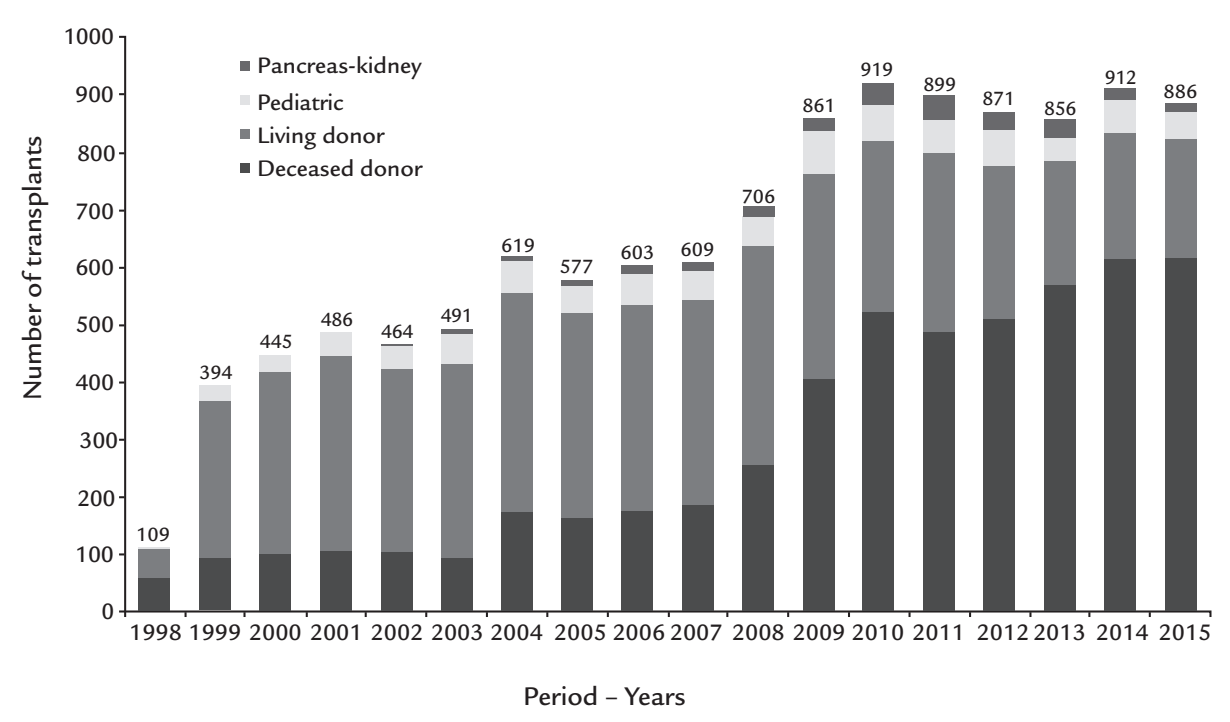

FIGURE 1 Annual number of transplants carried out at Hospital do Rim from August 18, 1998 to December 31, 2015, stratified by type of transplant: deceased, living, pediatric, and pancreas-kidney.

transplants from a living donor was 436 , and the average time of the donor and recipient until the transplant was scheduled was 12 days. In 2015, 886 transplants were carried out at the hrim, including 617 from deceased donors, 205 from living donors, 48 pediatric transplants, and 16 kidney and pancreas transplants.

\section{Quality control}

Healthcare quality indicators are analyzed weekly. The global surgical complication rate directly related to the transplant procedure remains stable at around $6.5 \%$, most of which are restricted to the surgical wound, and responsible for graft loss in $1.1 \%$ of transplants. The surgical technique currently used reduces or even eliminates any objective advantage of laparoscopic nephrectomy of the donor, the cost of which is significantly higher.

The average hospital stay is 8.2 days for recipients of a kidney from living donors and 12.5 days with kidneys from deceased donors. The early hospital readmission rate (less than 30 days after hospital discharge after the transplant), an indicator increasingly used by health insurers, is $26.6 \%$.

Between 2005 and 2015, reductions were noted in the infection rates of the surgical site ( $6.3 v$ s. $2.5 \%)$, urinary tract infection (18.1 vs. 4.4\%) and ventilation-associated pneumonia ( 25 vs. 0.4 per 1,000 cases of mechanical ventilation/day). On the other hand, there was a fluctuation in the rate of bloodstream infections, with 5.5 cases per 1,000 central venous catheters per day in $2005,13.4$ in 2007 , and 2.6 in 2009. In 2015, the rate was 8.3 cases per $1,000 /$ day, similar to other institutions, and probably associated with the increased incidence of infections caused by multiresistant bacteria (Figure 2).

\section{Performance of the support units}

In the period between 2003 and 2015, the immunogenetics laboratory increased the number of HLA system typing $(4,203$ to 4,374), sensitization tests for detection of anti-HLA antibodies in the serum $(8,720$ to 13,216$)$, and cross-matching $(5,670$ to 14,577$)$. The number of laboratory tests conducted by the laboratory increased 4.8 times between 1999 and 2015. In 2015, the number of tests conducted was $1,097,329$, including determinations of the plasma and blood concentrations of immunosuppressive drugs. At the day hospital unit, an average of six biopsies of transplanted kidneys were conducted per day to investigate specific causes of dysfunction, as well as treating an average of five patients per day for outpatient treatment of infections, anemia and episodes of rejection of the transplanted kidney. The pathology lab processed and issued reports for 551 kidney biopsies on deceased donors and 2,500 on transplanted kidneys. The hemodynamic service, which also serves the general population, conducted 2,033 diagnostic coronary angiograms, 524 angioplasties with and without implantation of stents, as well as 49 angioplasties for treating stenosis of the artery of the transplanted kidney.

\section{Efficiency in monitoring after the transplant}

At the end of 2015, the number of patients being monitored at the post-transplant unit was 7,751 (Table 1). In 


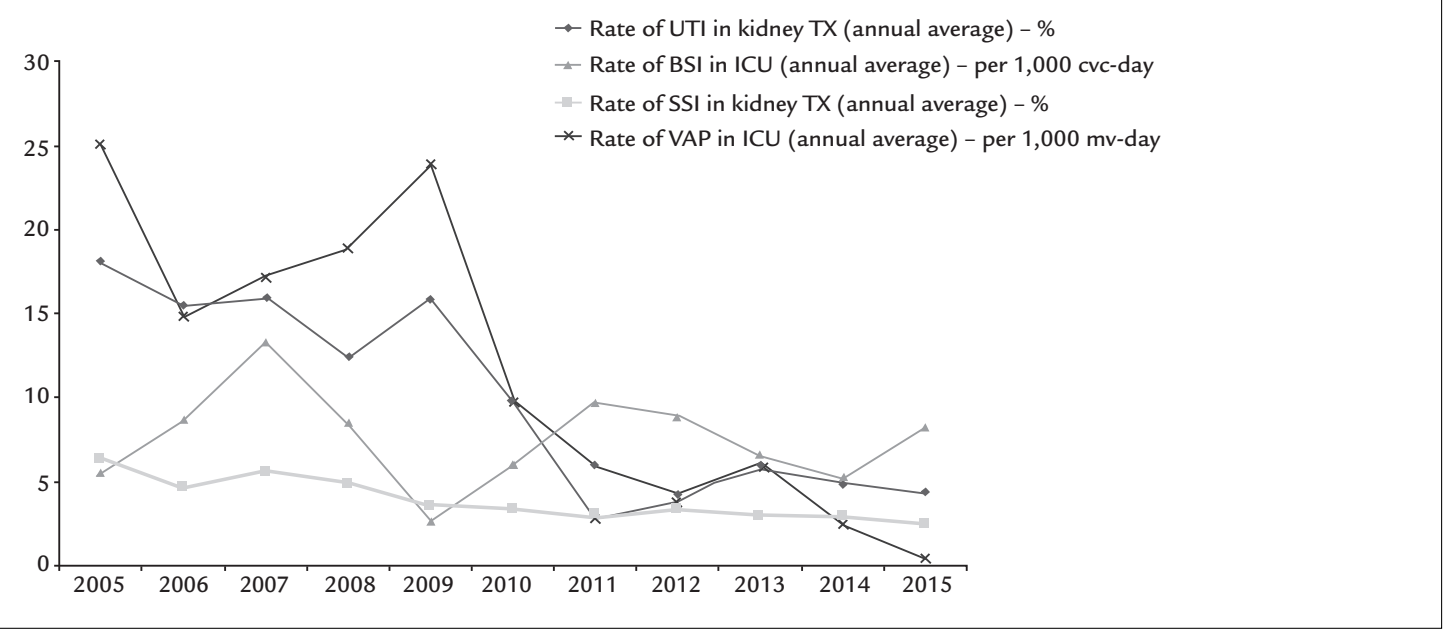

FIGURE 2 Indicators from the Hospital Infection Control Committee during the period from 2005 to 2015 for urinary tract infection,

bloodstream infection, surgical site infection, and pneumonia associated with ventilation.

UTI: urinary tract infection; TX: transplant; BSI: bloodstream infection; ICU: intensive care unit; SSI: surgical site infection; VAP: ventilation-associated pneumonia; cvc: central venous catheter; mv: mechanical ventilation.

the same year, 59,781 medical evaluations were conducted, meaning an average of 237 daily evaluations.

\section{Improvement of the survival results}

The performance of a kidney transplant center is classically evaluated by graft survival, calculated as the percentage of transplant patients who complete the first year with the functioning kidney, stratified by the type of donor, living or deceased. It has been noted that cumulative graft survival in the first year for transplants from 1998 to 2002 was $89.2 \%$, while for transplants from 2011-2014, graft survival was $92.5 \%$. Graft survival in transplants with living donors increased from $93.9 \%$ in $1998-2002$ to $97.2 \%$ in $2011-2014$, and from 77.4 to $90.4 \%$ with deceased donors (Figure 3). Similarly, the survival of patients in transplants from a living donor increased from $97.8 \%$ in 1998-2002 to $98.7 \%$ in 2011-2014, and from 90.5 to $95.1 \%$ with deceased donors. Sixty percent (60\%) of the 5,189 patients undergoing kidney transplants from deceased donors between 1998 and 2014 completed one year after transplant with graft function considered as excellent (creatinine less than $1.5 \mathrm{mg} / \mathrm{dL}$ ). This proportion was $66 \%$ for the 5,377 recipients of kidney transplants from living donors conducted in the same period.

In relation to the 11,436 kidney transplants carried out between 1998 and 2015, 68\% of patients are under monitoring, $12 \%$ lost graft function and returned to dialysis treatment, $12 \%$ died and $8 \%$ were transferred or no longer monitored at our unit. The most frequent cause of death was infection (53\%), followed by cardiovascular complications (16\%).

\section{Education and Research Program}

The large number of transplants conducted annually has enabled participation in national and international multicenter clinical studies, which are also important for identifying the best immunosuppressive regime in different types of patients, taking into account that the demographic characteristics of the Brazilian population differ from American and European populations. Between 1998 and 2015, over 3,000 patients were included in more than 60 phase I to IV clinical studies, contributing significantly to the adoption of new forms of immunosuppression by the regulatory agencies in the United States, Europe, and Brazil. Treatment strategies being investigated and validated at the hrim are subsequently adopted by various transplant centers in Brazil and abroad. In parallel, a training and education program in clinical research for pharmacists has been developed, involving 83 students that subsequently entered the labor market, whether in pharmaceutical industries, private companies or academic clinical research centers.

The growth of research and education activities led to the creation of the Education and Research Center (NEP, in the Portuguese acronym) in 2014. Between 1998 and 2015, 1,276 physicians, including 1,176 from Brazil and 100 from other countries, mainly in Latin America, participated in medical education activities at the hrim. In 2015, 364 undergraduate students, 49 residents (nephrol- 


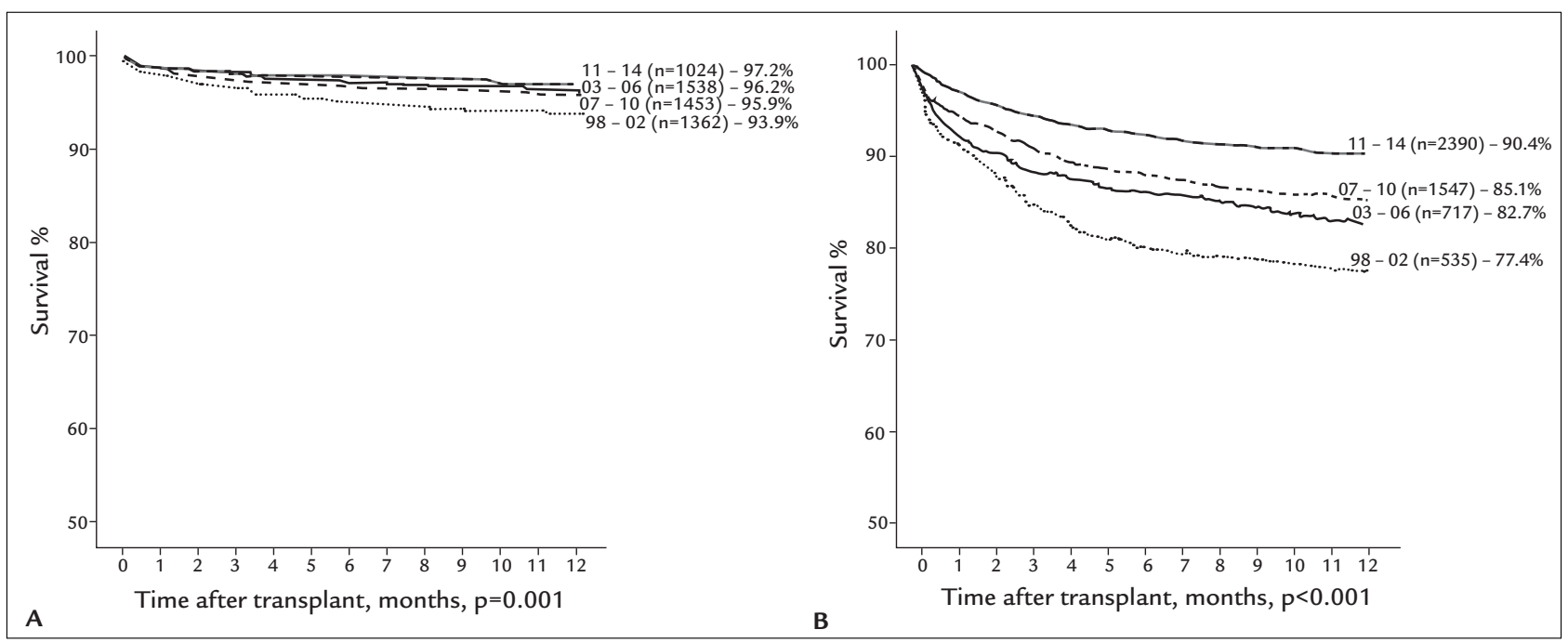

FIGURE 3 A. 12-month graft survival in recipients of kidney transplants from living donors in the period from 1998 to 2014 . B. 12-month graft survival in recipients of kidney transplants from deceased donors in the period from 1998 to 2014.

ogy, urology, cardiology, infectious diseases, multidisciplinary, and pharmacy) and 136 interns were trained. In the same year, 17 scientific studies were conducted, including four doctoral dissertations and 13 master's degree theses, as well as 15 articles published in indexed journals and 75 papers presented at national and international conferences. At the national level, this model of continuing education has led to the creation of new transplant centers in several states and increased activity at existing centers.

\section{Discussion}

The hrim's transplant model is based on maximum specialization, systematic repetition, and improvement of processes by all of the professionals involved in each of its modules. This model, which has enabled a significant increase in the number of transplants performed, has also provided academic and healthcare training for professionals dedicated to this therapeutic area throughout the national territory, also including the country in the international context of clinical research in the area. ${ }^{10}$ On two occasions, it has received approval by the Food and Drug Administration (FDA) as well as several hospital quality certifications, including national accreditation with excellence (Level 3) from the National Accreditation Organization (ONA), teaching hospital certification from the Ministry of Education and Culture and the Ministry of Health.

The efficiency and interconnection of the modules has influenced all of the performance metrics. In 1998, $75 \%$ of transplants were performed with kidneys from live donors, while from 2009 on the number of transplants with kidneys from deceased donors increased, reaching
$76 \%$ of transplants performed in $2015 .{ }^{11,12}$ The growth in the number of deceased donors, as well as the marked progress in dialysis assistance, has enabled us to apply more stringent criteria for kidney transplants from living donors. These restrictions are based on surgical risk (mortality rate after kidney donation at 3 per 10,000), and uncertainty about the risks of developing chronic kidney disease in the long-term, considering the progressive increase in the life expectancy of the general population.

The largest share of revenues is the result of remuneration for healthcare production by the SUS (62\%) as well as supplementary health providers. A small fraction comes from clinical research activities or the obtainment of additional public funds. The remuneration of the medical team is variable depending on the intensity of their participation in the program. The production, administrative, and financial indicators are subject to monthly external audits and presented semiannually to the board of trustees and the Public Ministry through its trustee of foundations. This hierarchy of controls demands permanent administrative rigor, but the budget balance of the service to the SUS depends on surplus revenue from the service to patients treated under supplementary medicine and, to a lesser extent, from additional public funds.

\section{Perspectives}

The transplant model performed at the hrim results in increased productivity, efficiency, and progressive improvement of outcomes. This model can be applied in other medical intervention methods whose prevalence requires a large-scale care, such as the treatment of benign pros- 
tatic hypertrophy, nephrolithiasis, ophthalmologic disorders, several types of cancer, implantation of orthopedic prostheses, and myocardial revascularization.

In our view, the greatest benefit of using this model could occur in developing countries, with limited availability of high complexity treatments for highly prevalent diseases. In these regions, the implementation of this model, even when restricted to a single institution, could offer effective treatments on a large scale for the majority of the population. Whatever the scenario, the application of this model for increased efficiency requires the principles of scientific management, introduced by Frederick Taylor and universally refined, to be incorporated and continuously enhanced by all the members of the institution.

\section{Resumo}

Um modelo pioneiro de aplicação dos conceitos da produção em larga escala na assistência à saúde: princípios e desempenho em mais de 11 mil transplantes no Hospital do Rim

O programa de transplante renal do Hospital do Rim (hrim) é um modelo único de assistência médica que aplica os princípios da repetição de processos utilizados na produção industrial. Esse modelo, idealizado por Frederick Taylor, é fundamentado em princípios da administração científica, que envolvem planejamento, execução racional do trabalho e distribuição de responsabilidades. O resultado esperado é o aumento da eficiência, melhoria dos resultados e otimização de recursos. Esse modelo, quase todo subsidiado pelo Sistema Único de Saúde (SUS), foi utilizado no hrim para a realização de mais de $11 \mathrm{mil}$ transplantes nos últimos 18 anos. O modelo do hrim consiste em oito módulos interconectados: organização de procura de órgãos, preparo para o transplante, admissão para transplante, procedimento cirúrgico, pós-operatório, seguimento pós-transplante, unidades de apoio, e coordenação e controle de qualidade. O fluxo das atividades médicas permite o atendimento organizado e sistemático de todos os pacientes. O aperfeiçoamento das atividades de cada módulo é constante, com monitora- mento integral de diversos indicadores administrativos, assistenciais e de desempenho. A melhora contínua dos resultados clínicos confirma a eficiência do programa. Entre 1998 e 2015, foi observado um aumento nas sobrevidas do enxerto (77,4 vs. 90,4\%; $\mathrm{p}<0,001)$ e do paciente $(90,5 \%$ vs. $95,1 \% ; \mathrm{p}=0,001)$, respectivamente. A elevada produtividade, a eficiência e a melhoria progressiva dos resultados obtidos sugerem que esse modelo pode ser aplicado em outras áreas terapêuticas que necessitam de assistência em larga escala, sem comprometer os conceitos humanísticos de nossa atividade assistencial.

Palavras-chave: transplante renal, organização de procura de órgãos e tecidos, insuficiência renal, Sistema Único de Saúde.

\section{References}

1. Constituição da República Federativa do Brasil. 1988

2. Medina-Pestana JO, Vaz ML, Park SI, Garcia VD, Abbud-Filho M, Campos Hde H. Organ transplantation in Brazil in the year 2002. Transplantation Proc. 2004; 36(4):799-801.

3. Órgão ABdTd. RBT Registro Brasileiro de Transplante. Veículo oficial da Associação Brasileira de Transplante de Órgãos. Dimensionamento dos transplantes no Brasil e em cada estado (2008- 2015). 2015.

4. Medina-Pestana JO. Organization of a high-volume kidney transplant program - The "Assembly line" approach. Transplantation. 2006; 81(11):1510-20.

5. Medina-Pestana JO. More than 1,000 kidney transplants in a single year by the "Hospital do Rim" Group in Sao Paulo - Brazil. Clin Transpl. 2010:107-26.

6. Medina-Pestana JO, Galante NZ, Tedesco-Silva H Jr, Harada KM, Garcia $\mathrm{VD}$, Abbud-Filho M, et al. Kidney transplantation in Brazil and its geographic disparity. J Bras Nefrol. 2011; 33(4):472-84.

7. Pestana JM. Jose Medina Pestana, MD, PhD, FRCS: Head of Transplant Division. Transplantation. 2016; 100(1):7-9.

8. Medina-Pestana JO, Sampaio EM, Santos TH, Aoqui CM, Ammirati AL, Caron D, et al. Deceased organ donation in Brazil: how can we improve? Transplant Proc. 2007; 39(2):401-2.

9. Baptista-Silva JC, Poli de Figueiredo LF, Câmara AL, Demuner MS, Castro MJ, Verissimo M, et al. Outcome of 605 consecutive living donor nephrectomies through an anterior subcostal retroperitoneal approach. Transplant Proc. 2002; 34(2):451-2.

10. Silva HT Jr, Felipe CR, Abbud-Filho M, Garcia V, Medina-Pestana JO. The emerging role of Brazil in clinical trial conduct for transplantation. Am J Transplant. 2011; 11(7):1368-75.

11. Alvares J, Falleiros DR, Barbosa MM, Almeida AM, Araujo VE, Guerra Junior AA, et al. [Budget impact analysis: would the Brazilian public health system increase, by means of transplants, the cost of treatment of chronic terminal kidney disease?] Value in Health. 2013 ;16(7):A665.

12. Assis-Borba L, Cristelli MP, Paula MI, Franco MF, Tedesco-Silva H, MedinaPestana JO. Expanding the use of expanded criteria donors in kidney transplantation. Int Urol Nephrol. 2014; 46(8):1663-71. 